Editorial

\title{
Tecnologias de Informação (TI) na Educação
}

\section{Information Technology (IT) in Education}

\author{
Maria José Angélico ${ }^{1}$ Álvaro Rocha ${ }^{2}$ \\ mjose@iscap.ipp.pt, amrocha@dei.uc.pt \\ ${ }^{1}$ Instituto Politécnico do Porto/ISCAP/CICE, CEPESE, Rua Jaime Lopes Amorim, s/n \\ 4465-004 S. Mamede de Infesta, Portugal. \\ ${ }^{2}$ Universidade de Coimbra, Departamento de Engenharia Informática, Pólo II - Pinhal de Marrocos, 3030- \\ 290 Coimbra, Portugal.
}

DOI: 10.17013/risti.16.ix-xi

\section{Introdução}

A expressão sociedade da informação e do conhecimento é indissociável dos processos de globalização económica capitalista e do atual papel dos Estados nacionais. Por esta razão, muitos dos teóricos da sociedade da informação invocam as escolas e os sistemas educativos como parte fundamental do processo de mudança ambicionado.

Neste contexto, as Tecnologias de Informação (TI) assumem um papel determinante, sendo hoje reconhecidas pela sociedade, nomeadamente a comunidade científica, como um instrumento primordial para a concretização da aquisição e transferência de conhecimento e, concomitantemente, para a modernização, reforma e transformação do processo educativo, há vários anos.

Assim, o número dezasseis da revista RISTI (Revista Ibérica de Sistemas e Tecnologias de Informação) debruça-se sobre as Tecnologias de Informação aplicadas à Educação, tomando por objeto o novo paradigma de ensino/aprendizagem e a consequente definição de novas metodologias, estratégias e técnicas de ensino e o aparecimento de novos recursos educativos no contexto atual.

O conjunto de nove artigos que se publica neste número da RISTI resultou de um escrutínio exímio efetuado pelos membros da comissão científica sobre os cinquenta e cinco trabalhos apresentados pelos autores, oriundos quinze de Portugal, nove do Equador, nove do Brasil, oito de Espanha, seis da Colômbia, três do México, dois da Argentina, dois da República Dominicana e um de França, correspondendo a uma taxa de aceitação de $16 \%$. 


\section{Estrutura}

Para facilitar a leitura desta edição, optou-se por apresentar, em primeiro lugar, as contribuições que apresentam estratégias, técnicas e recursos educativos que asseguram a transmissão/receção do conhecimento, dotando os estudantes de competências específicas da área em estudo e competências transversais e, em seguida, os artigos que, embora se enquadrem em contexto de ensino, são de âmbito mais genérico. Assim:

- No primeiro artigo, os autores descrevem um estudo que apresenta a gamificação como estratégia didática no ensino da matemática. O estudo, onde estiveram envolvidos dois mil duzentos e sessenta e três estudantes, demonstrou que a utilização dessa estratégia aumenta o desempenho académico dos alunos e diminui a taxa de abandono.

- O segundo artigo expõe uma investigação que teve como objetivo compreender a adesão e o potencial dos jogos de simulação na educação superior. Nas práticas da unidade curricular de "Simulação de Marketing", do curso de Licenciatura em Gestão, da Universidade do Algarve, foi utilizado o jogo "Cesim SimBrand". Analisados os dados, resultantes de um questionário distribuído aos estudantes, os autores concluíram que a característica-chave apontada pelos inquiridos foi: o jogo referido permite uma competição realista, o que possibilita um melhor entendimento das principais áreas de negócio envolvidas.

- No artigo seguinte, é descrito o desenvolvimento do jogo "Konnecting" para plataforma mobile, bem como as etapas envolvidas na sua implementação. $\mathrm{O}$ artigo termina explicitando as mecânicas dejogo, e os princípios de aprendizagem subjacentes.

- O quarto artigo apresenta um estudo que relata a aplicação do Portfolio Europeu das Línguas eletrónico (e-PEL) na Escola Oficial de Idiomas de Alicante. O estudo demostrou, utilizando uma abordagem qualitativa e quantitativa, que o e-PEL contribuiu positivamente para a aquisição de competências e estratégias linguísticas.

- O quinto artigo descreve um projeto de inovação docente e defende a relevância do uso dos videojogos na demonstração, de forma muito visual e didática, do funcionamento das diversas ferramentas de Lean Manufacturing, em particular a metodologia 5 S. No trabalho realizado, os autores concluíram que o uso do Minecraft revelou-se um êxito.

- No sexto artigo, os autores apresentam o desenvolvimento de um videojogo multiutilizador, baseado em realidade virtual, cujo objetivo é promover o desenvolvimento de soft-skills, especificamente o trabalho em grupo.

- No sétimo artigo, os autores expõem um novo modelo de e-learning, cujo objetivo fundamental é combinar os paradigmas e-learning e redes sociais. As ações dinâmicas, colaborativas e altamente relacionais e interativas, características das redes sociais, contribuem para minimizar o impacto da falta de relacionamento humano, característica associada ao e-learning.

- O oitavo artigo apresenta um trabalho de investigação, cujo objetivo é introduzir um novo modelo de comunicação entre a escola e a família. Os autores definem a Caderneta Eletrónica como um instrumento facilitador e potenciador de estabelecimento de relacionamentos entre a comunidade educativa, mais precisamente entre professores, encarregados de educação e estudantes. 
- O último artigo resultou de uma investigação que teve por objetivo avaliar o tipo e o grau com que são experienciadas as emoções no contexto do ensino num ambiente virtual. Examinadas as propriedades psicométricas de um questionário, composto por duas escalas de Bem-estar e de Mal-estar emocional, os autores concluíram que a validação portuguesa das duas escalas revelou boas propriedades psicométricas.

\section{Agradecimentos}

Termina-se esta introdução, expressando o nosso agradecimento a todos os autores e revisores envolvidos nesta edição, esperando que este número da RISTI se revele uma leitura profícua para todos os que se mobilizam em torno da problemática das Tecnologias de Informação na educação. Um agradecimento especial à AISTI, proprietária e promotora da RISTI, à Academic Journals Database, CiteFactor, Compendex, Dialnet, DOAJ, DOI, EBSCO, GALE, IndexCopernicus, Index of Information Systems Journals, ISI Web of Knowledge, Latindex, ProQuest, QUALIS, SciELO, SCImago e Scopus, entidades que tem contribuído para tornar a RISTI uma referência neste competitivo mercado das revistas científicas. 